\title{
A narrativa gráfica underground e a linha suja
}

\section{The underground graphic narrative and the dirty line}

DOI: $10.46814 /$ lajdv3n3-012

Recebimento dos originais: 01/05/2021

Aceitação para publicação: 30/06/2021

\section{André Inácio de Assunção Neto}

Mestre em História Social pela Universidade Federal do Rio de Janeiro - UFRJ. É professor de História do Instituto Federal do Tocantins - IFTO. Endereço: Rua B, 1579, Vila Frazão, Araguatins - TO

E-mail: andre.assuncao@ifto.edu.br.

\section{RESUMO}

Neste artigo pretendemos compreender a narrativa gráfica underground no que diz respeito à obsessão de seus autores por temáticas marginais e conteúdos sujos. Para isso, investigamos a linha suja dos quadrinhos considerando tanto questões de ordem sócio-histórica, em um nível por vezes mais geral, quanto aspectos editoriais e estéticos, específicos do campo da narrativa gráfica.

Palavras-chave: História em quadrinhos, Narrativa gráfica underground, Linha suja.

\section{ABSTRACT}

In this article we intend to understand the underground graphic narrative with regard to its authors' obsession with marginal themes and dirty content. To this end, we investigated the dirty line of comics considering both socio-historical issues, on a sometimes more general level, and editorial and aesthetic aspects, specific to the field of graphic narrative.

Keywords: Comics, Underground graphic narrative, Dirty line.

\section{A OPÇÃO PELO "BAIXO”}

Na abertura de Pasadas anales, quadrinho em oito páginas de Rand Holmes ${ }^{1}$, publicado em 1980 na famosa revista El Víbora, acompanhamos o seguinte: um rato vasculha a lata de lixo enquanto é espreitado por um gato. Ele se lastima por só encontrar coisas inúteis quando, repentinamente, o felino se lança em sua direção ansioso por abocanhá-lo. O roedor, lépido, se esquiva do ataque e, num contragolpe, atinge violentamente o bichano com a tampa metálica da lixeira. Sem hesitar, a pequena criatura ruma sôfrega em direção à sua toca, e o gato, já recomposto, tenta nova investida. Antes de entrar no covil, no limite de ser alcançado, o rato puxa o pino de um dispositivo de emergência, uma espécie de armadilha preparada para situações daquele tipo. As consequências: um motor suspenso é solto e atinge a cabeça do bichano, que termina espatifada (FIG. 1).

\footnotetext{
${ }^{1}$ Rand Holmes pode ser facilmente citado entre os mais respeitados quadrinistas canadenses. Com Harold Hedd, seu herói hippie, ganhou fama nas cenas "contraculturais" emergentes que, como o personagem, demonstravam repulsa aos "bons valores” ocidentais e, logo, enalteciam o amor livre, abusavam de drogas e evitavam o trabalho. Os trabalhos de Holmes se espalharam por vários países com a popularização dos quadrinhos underground no começo dos anos de 1970.
} 
FIG. 1 - Passadas Anales, Rand Holmes. Fonte: El Víbora nº 13-14 (1980).

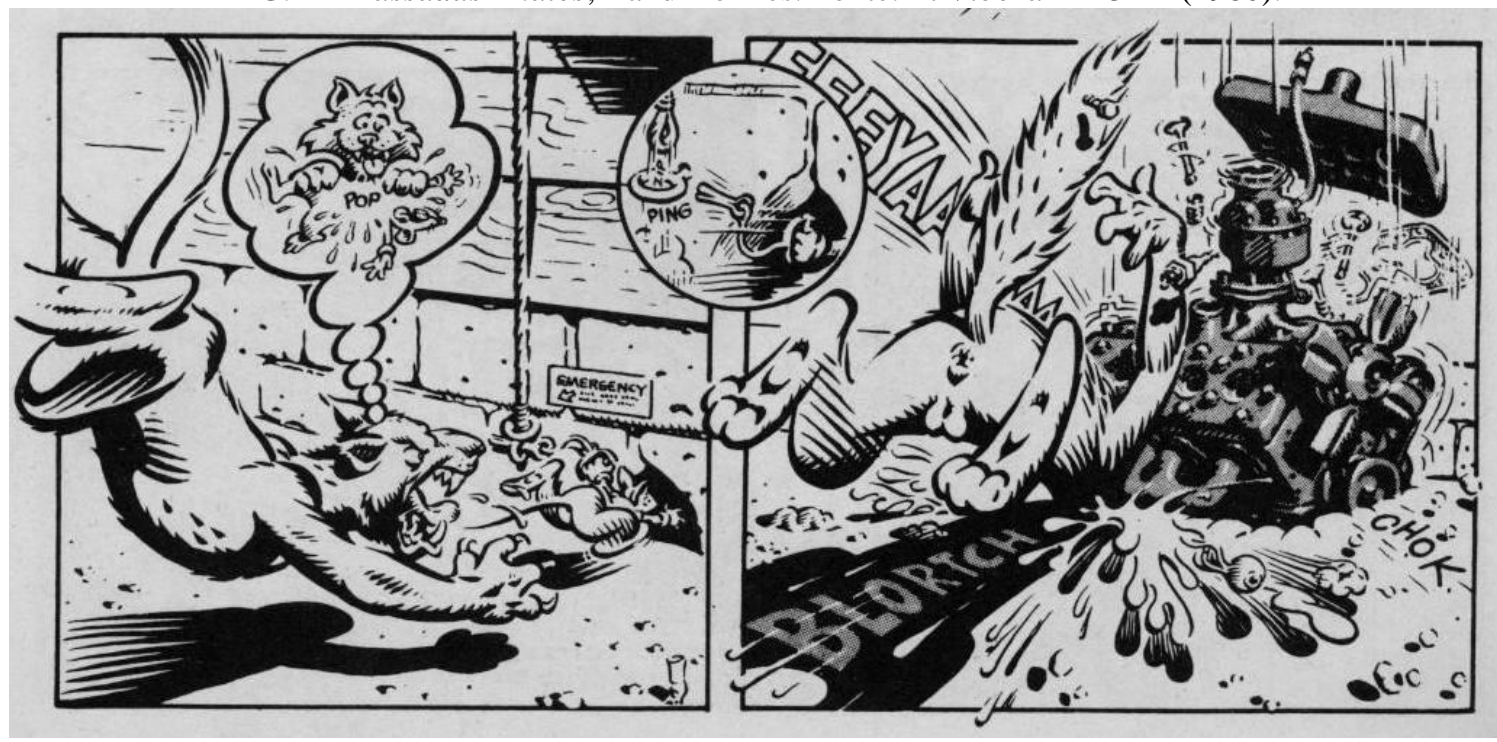

O prelúdio de Pasadas anales evoca as cômicas aventuras de Tom \& Jerry, uma das duplas de animais antropomórficos mais bem-sucedidas dos desenhos animados (criada em 1940 pelos prolíficos William Hanna e Joseph Barbera). Nas tramas de Hanna e Barbera, o rato, astuto e ágil, é constantemente caçado por seu rival felino, um gato doméstico, que apesar de recorrer a artimanhas e armadilhas mirabolantes, se mostra com frequência equivocado e estúpido, sempre deixando o roedor escapar. Ambos os personagens apresentam características de sadismo em sequências carregadas de humor e muita violência - sequências em que na grande maioria das vezes o gato se dá mal, e quando se dá bem é transitoriamente. Entretanto, como é comum na realidade dos cartuns, mesmo passando por explosões, pancadas impetuosas, quedas inacreditáveis, que marcam e esfolam ${ }^{2}$ seus corpos, os heróis terminam absolutamente e instantaneamente recompostos após cada evento, como se nada houvesse acontecido, prontos para recomeçar a infindável saga de caça, fuga e destruição bemhumorada.

Encontramos no prelúdio de Holmes elementos que o aproximam de Tom \& Jerry, mas há nele distorções, pelo próprio sentido paródico, que o coloca em outras linhas de composição, expressando o que podemos tratar como traços fundamentais dos quadrinhos underground, objeto de nosso artigo. Nip (o rato de Pasadas Anales), ardiloso e diligente como Jerry, escapa repetidamente dos botes apressados, para então, de súbito, esmagar de uma vez por todas os miolos de seu perseguidor. Somos conduzidos, desde os movimentos iniciais, pelas veredas da matéria "baixa": se nunca se viu as partes baixas de Tom ao longo de sua longeva trajetória, o gato de Holmes, em sua efêmera existência, aparece

\footnotetext{
${ }^{2}$ Os efeitos da violência eram minimizados nas retratações, já que se tratava de uma série produzida com destino a crianças - ou ao público mais amplo possível.
} 
com o ânus e o escroto expostos enquanto seu crânio é violentamente espatifado (vide novamente a FIG. 1).

Pasadas anales segue por caminhos que levam a profundezas um tanto mais repulsivas, como veremos. Mas antes, acreditamos ser importante destacar que a escolhemos justamente porque, além de ser um exemplar muito representativo da linhagem underground de quadrinhos, foi concebida por um de seus importantes nomes, considerado inclusive um dos patriarcas do comix ${ }^{3}$ ao lado de ícones como Robert Crumb e Gilbert Shelton, embora certamente menos conhecido que estes. Há também o fato de que é um trabalho publicado na espanhola El Víbora, provavelmente uma das mais relevantes e longevas revistas voltadas para a publicação de quadrinhos sujos, editada de 1979 a 2005, com mais de 300 números publicados.

El Víbora se consagra no início da década de 1980 como a revista "oficial” da linha suja (ou linea chunga) dos quadrinhos na Espanha, mas a publicação era um verdadeiro aglutinador de trabalhos underground dos quatro cantos do mundo. Ela é, em muitos aspectos, fruto do impulso original dado anos antes nos Estados Unidos e provavelmente representa um dos grandes momentos dessa linhagem de quadrinhos no mundo. A maior diferença para suas matrizes talvez seja o fato de que a publicação espanhola contava com meios, digamos, industriais de publicação e distribuição. Gerard Jones descreve como o processo funcionava nos anos de 1960, nos primórdios dos quadrinhos underground:

\begin{abstract}
Jovens cartunistas satíricos, como Robert Crumb e Art Spiegelman, começaram na época a procurar novos espaços para seu trabalho. Alguns colaboravam em periódicos modestos, produzidos pela esquerda radical pacifista, como The Realist, criado por um ex-office boy da EC, Paul Krassner. Outros publicavam em "jornais de vanguarda" que começaram a surgir em torno da cultura hippie: The East Village Other, Yarrowstalks e The Berkeley Barb. Depois parte deles começou a perceber que poderia criar suas próprias revistas em quadrinhos, versões mais bem-feitas dos fanzines da juventude, e distribuí-las pelos mesmos canais usados pela imprensa de esquerda e de vanguarda: estabelecimentos que surgiam em torno das faculdades de todo o país, como livrarias alternativas, bares hippies e lojinhas com toda a parafernália para consumo de maconha. As próprias ruas se tornavam local de distribuição: Robert Crumb vendia a Zap Comics na Haight Street, em San Francisco, com a ajuda de um carrinho de bebê (Jones, 2006, p. 363).
\end{abstract}

A condição de marginalidade limitava sem dúvida a circulação das HQs underground. Como seus autores desconsideravam o Comics $\operatorname{Code}^{4}$, suas histórias não podiam ser vendidas em bancas de revistas ou supermercados, os pontos de venda usuais dos quadrinhos. A saída era improvisar e vender da forma que desse. A associação com os meios de produção e distribuição de uma variada imprensa

\footnotetext{
${ }^{3}$ Os quadrinhos underground norte-americanos, no processo de se diferenciar dos quadrinhos convencionais, mudam a grafia já conhecida de "comics" para "comix", que então passará a ser sua marca.

${ }^{4}$ Em 1954 foi publicado o livro The Seduction of The Innocent, de autoria do médico Frederic Wertham, obra que é usualmente citada como o estopim para que surgisse nos Estados Unidos o Comics Code Authority, o "Código de Ética" para as histórias em quadrinhos. Sua função era coibir as publicações que estariam envenenando a mente da infância e da juventude com conteúdos altamente nocivos, mostrando monstros deformados e violência gratuita.
} 
marginal e rebelde, referida por Gerard Jones, parece ter ocorrido de forma espontânea, uma vez que os próprios quadrinhos underground eram marginais e se "distinguiram rapidamente por sua enfurecida rebelião contra a moral vigente" (García, 2012, p. 166).

Santiago Garcia lembra que “em 1971, quando as HQs underground já tinham se consolidado, as tiragens médias dos títulos mais populares podiam chegar aos 20 mil exemplares”. Gilbert Shelton, um dos mais cultuados, chegou a vender 200 mil cópias de uma mesma edição em 1973. Era o sinal mais claro de que os quadrinhos rebeldes tinham caído nas graças de uma legião de leitores. Mas Garcia pede para relativizarmos a popularidade dos quadrinhos underground, que apesar desses números, inegavelmente expressivos, ainda era um segmento marginal se considerarmos o volume de vendas da grande indústria de quadrinhos na mesma época (García, 2012, p. 166).

A popularidade nos Estados Unidos leva nascentes editoras alternativas do continente europeu a se interessarem pelo material e já no início dos anos de 1970 as HQs underground circulam por França, Itália, Holanda, Alemanha, Espanha. A difusão, no entanto, como podemos supor, não ocorre de maneira uniforme. Os espanhóis, para citar apenas um exemplo, ainda enfrentando os suspiros finais do regime franquista, veriam sua primeira compilação de material underground em 1972, no primeiro volume da antologia Comix Underground USA, edição em forma de livro, traduzida e "retocada" para atendar às exigências dos aparelhos institucionais de censura. Os "retoques", todavia, não impediram que muitos leitores de quadrinhos conhecessem, ainda que de maneira incompleta, e se identificassem com o tom subversivo das histórias. Nessa primeira publicação espanhola com material norteamericano, como também aconteceu em outros países, muitos jovens desenhistas encontrariam as bases estéticas pelas quais desenvolveriam seus estilos. É o caso de praticamente todos os jovens e promissores quadrinistas espanhóis que se tornaram "famosos" nas páginas de El Víbora.

\section{A NARRATIVA GRÁFICA UNDERGROUND}

Quando surgem as primeiras histórias em quadrinhos underground norte-americanas, já se vê nelas uma evidente afinidade com a matéria "baixa"5: conteúdos obscenos, escatológicos, ultraviolentos, asquerosos, proibidos, etc. Elas se proliferam, como vimos, ainda no início dos anos de 1960 em revistas na imprensa alternativa (com capacidade para relativo volume de produção, embora de forma praticamente artesanal se comparada à grande indústria), nas universidades, em torno de grupos politizados de esquerda, ativistas, hippies. Tinham como principais características, basicamente, o traço caricatural carregado (sujo), a crítica social e os temas anti-establishment

\footnotetext{
${ }^{5}$ Sobre a matéria "baixa", nos fundamentamos principalmente no conceito cunhado por Bakhtin (1987) em seus estudos sobre Rabelais.
} 
abordados pelo caminho do humor, da ridicularização, do escárnio e da ironia. No princípio são relativamente rudimentares (nos desenhos, no apuro estético, na qualidade gráfica), mas em pouco tempo despontam no cenário quadrinistas com inigualável talento, que definem os parâmetros do que se tornaria uma inspiração capital no mundo da narrativa gráfica.

Clay Wilson, Robert Crumb, Hand Holmes, Gilbert Shelton, Rick Griffin, Victor Moscoso, Robert Williams são alguns dos protagonistas do que para muitos foi uma verdadeira revolução no campo dos quadrinhos. Se podemos falar de HQs cínicas de humor, satíricas e paródicas, nas décadas anteriores a de 1960, quase nenhuma se engajou de maneira tão franca na experimentação ampla de conteúdos proibidos, de temas considerados repulsivos (FIG. 2) e de novas formas narrativas (e mesmo disnarrativas).

Os quadrinhos underground nascem, portanto, associados aos movimentos contraculturais e ao que se convencionou a chamar de era hippie. Sem dúvida uma conjuntura muito favorável ao florescimento de obras rebeldes. "Pela relativa liberdade de expressão que possuíam, a contracultura encontrou neles um veículo versátil e barato com que se podia expressar sem travas de nenhum tipo, convertendo-se em uma nova forma de protesto e reivindicação social” (DOPICO, 2011, p. 169). 
FIG. 2 - Robert Crumb em um de seus panfletos cômicos em prol de uma América melhor, ensina aos leitores o procedimento adequado para fumarem um cigarro de maconha e, assim, se livrarem das agruras que os assolam. Muitos o levaram a sério praticando a terapia. A página foi publicada originalmente em Zap Comix nº 0, de 1967. Fonte: Zap Comix (2005).

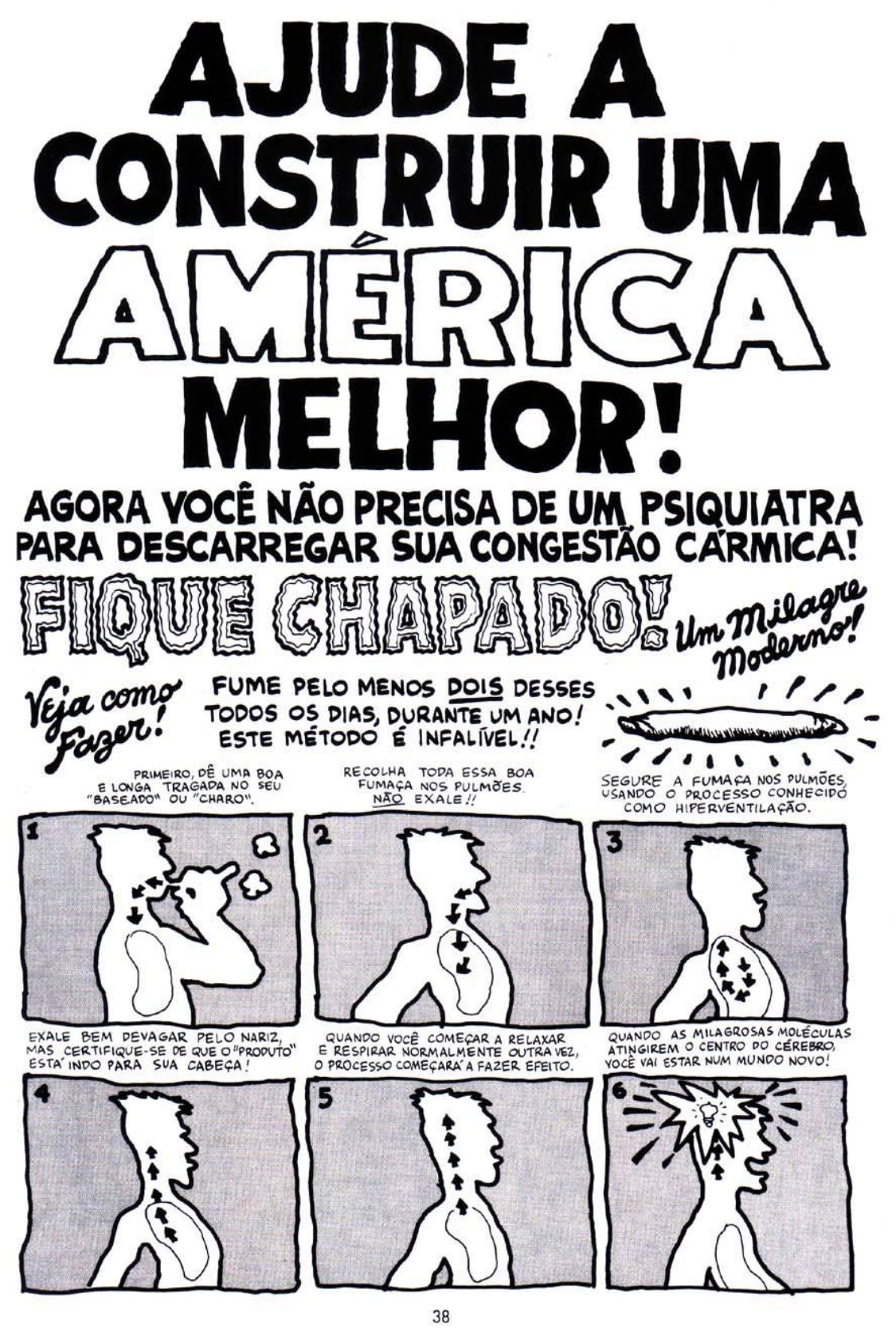

Surgia então um tipo de humor gráfico fortemente inclinado a navegar pelos mares agitados da iconoclastia e da transgressão, seja no que diz respeito à forma ou ao conteúdo. As inspirações vinham de trabalhos de uma infinidade de criadores da longa tradição do humor subversivo e das formas grotescas - indo, para citar o mais óbvio, de referências próximas no tempo como Jack Davis, Will Elder, Harvey Kurtzman, Wallace Wood, os responsáveis pela ousadia do humor ácido da revista Mad ${ }^{6}$,

\footnotetext{
${ }^{6}$ Os escritores da revista $M a d$ e os quadrinhos da editora EC Comics como um todo são citados como inspirações por praticamente todos os importantes escritores das HQs underground norte-americanas. Mad e outras publicações da EC seriam vítimas da política marcatista nos anos de 1950 nos Estados Unidos.
} 
ou Basil Wolverton ${ }^{7}$ (que publica desde os anos de 1920), com seu humor carregado de elementos gráficos truanescos, até as distantes e canônicas, como Dante, Rabelais, Bruegel ou Bosh. Não é de se surpreender, destarte, que investissem naquilo que normalmente era considerado feio, asqueroso e grotesco ou que era interditado e marginalizado pela maioria das pessoas.

\section{A ELEVAÇÃO VEM DE BAIXO}

Vejamos a seguir dois exemplos da grande engenhosidade dos autores underground nas figurações peculiares da matéria "baixa" e nas formas insólitas pelas quais ela aparece animada nas histórias. Para isso, voltaremos a Pasadas anales de Rand Holmes no intuito de demonstrar materialmente alguns aspectos das obsessões típicas desses quadrinistas. A sequência se desenrola imediatamente após o prelúdio apresentado na abertura deste artigo.

Dentro de sua escura habitação, Nip recebe os cumprimentos de seu amigo Tuk, outra ratazana, por acertar em cheio a cabeça do agora finado bichano. Esgotado, depois da forte tensão, ele segue até uma garrafa procurando álcool para acalmar os nervos. Fica enraivecido quando percebe que está sem sorte. Tuk, bem-humorado, brinca com o amigo dizendo que assim ele estará livre de uma hemorragia intestinal, mas, em seguida, avisa que os moradores humanos do subsolo sempre têm bebida em quantidade. Imediatamente descem e, já no sótão, não acham nada além de cadáveres de garrafas e latas. Nip, aborrecido, pensa em outra estratégia: "Se não podemos beber, vamos fumar... O cara cabeludo de cima geralmente tem mandanga [gíria para maconha] à beça”. Os ratos correm até lá. Mais uma vez sem sorte, se frustram ao encontrarem a polícia revistando o lugar, com o tal cabeludo detido. Tuk, visivelmente contrariado, questiona: “Todavia ainda não mudaram essa estúpida lei?”.

Eles não se dão por vencidos e, iluminados por nova ideia, seguem à cobertura do prédio para testarem as anfetaminas dos "gays", como diz Tuk. Depois de muito esforço para subir seis pisos pelas paredes, Nip, fatigado, admite resfolegante que lhe apetecerá um estimulante cardíaco. Dentro do apartamento, eles não encontram nada mais que corpos adormecidos, poças de esperma e lixo. Desiludidos depois de tudo, concluem não haver solução a não ser desistir e se lamentar por tanto azar, mas Tuk, ainda persistindo, e tomado por súbito entusiasmo, lembra o parceiro sobre a gorda do segundo piso que "sangra as hemorroidas". A lembrança não é benquista: "Por Deus, Tuk, você se tornou um idiota ou o quê!? Que me importa se o cu dela se parece com um saco de batatas germinadas". Apesar disso, ignorando o mau humor do amigo, ele restitui as esperanças ao acrescentar

\footnotetext{
${ }^{7}$ Alguns veteranos que inspiraram os quadrinistas underground, como Wolverton e Kurtzman, também foram publicados em El Víbora. Wolverton aparece nos números 2, 7, 8-9 e 11 e Kurtzman na edição especial USA de 1981, que contava ainda com Crumb, Wilson, Shelton, Griffth, Spiegelman, Holmes, Spain Rodriguez, Deitch e o próprio Wolverton.
} 
que, enquanto "cagava" $"$ na casa da tal gorda certa vez, viu por acaso uma caixa com supositórios de ópio.

Os ratos descem frenéticos e, já dentro do apartamento, correm até o criado-mudo onde ficam guardados os supositórios. Felizes em perceber que havia ainda um último e mais que suficiente invólucro com ópio, se deparam com a repentina entrada da mulher no quarto. Escondidos, veem-na pegar o estimado objeto, inseri-lo no ânus e então deitar-se para dormir. Os infortúnios do dia são intermináveis e Tuk, pela primeira vez, de fato desiste. Nip, furioso, se recusa a admitir a derrota tendo estado tão próximo do êxito. Ele segue até a mulher agora adormecida e diz que pretende retirar sua droga de lá a qualquer custo. Depois de algum esforço tentando mover as pomposas nádegas, o rato chega à conclusão de que será preciso ferramentas adequadas para a grotesca tarefa. Tuk busca a caixa de ferramentas do vizinho, um mecânico. Usando um macaco hidráulico para suspender as ancas da mulher e óleo para lubrificar o reto e facilitar a retirada do objeto, os ratos, ainda assim, não conseguem alcançar o supositório, que se mantem imerso nas profundezas. Nip observa que será preciso entrar para retirá-lo. É então que, devidamente equipado com uma máscara de oxigênio, ele mergulha no fétido orifício, que permanece alargado por um alicate sob o controle de seu cúmplice (FIG. 3).

Momentos depois, já de volta das entranhas, o roedor diz que o localizou, mas "o fodido traste está preso" e ele não é capaz de movê-lo. Não havendo alternativa, constata que só resta arrombá-lo. Tuk, surpreso e afetado por sentimento de compaixão, lembra das hemorroidas da mulher e questiona se não estão passando dos limites, numa tentativa de fazer seu obstinado e cruel colega mudar de ideia, mas este, impassível, segue com o plano. Carregam uma pequena bomba, introduzem-na no ânus da mulher, acendem e se protegem esperando a explosão. O forte estouro lança pelos ares, como esperavam, o tão desejado supositório de ópio. Nip, sem titubear, apara o invólucro antes que chegue ao chão.

\footnotetext{
${ }^{8}$ Os quadrinistas underground, procurando criar universos ficcionais com elementos "chulos" e "vulgares", moldam os diálogos de suas personagens de forma a evocar as tonalidades do discurso informal das ruas. Gírias, palavras "baixas", enfim, a forma coloquial das falas, são componentes recorrentes em suas obras.
} 


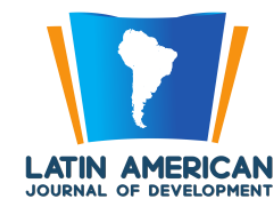

FIG. 3 - Passadas Anales, Rand Holmes. Nip, auxiliado por seu parceiro, adentra o ânus da mulher em busca do supositório de ópio. Fonte: El Víbora n ${ }^{\circ} 13-14$ (1980).
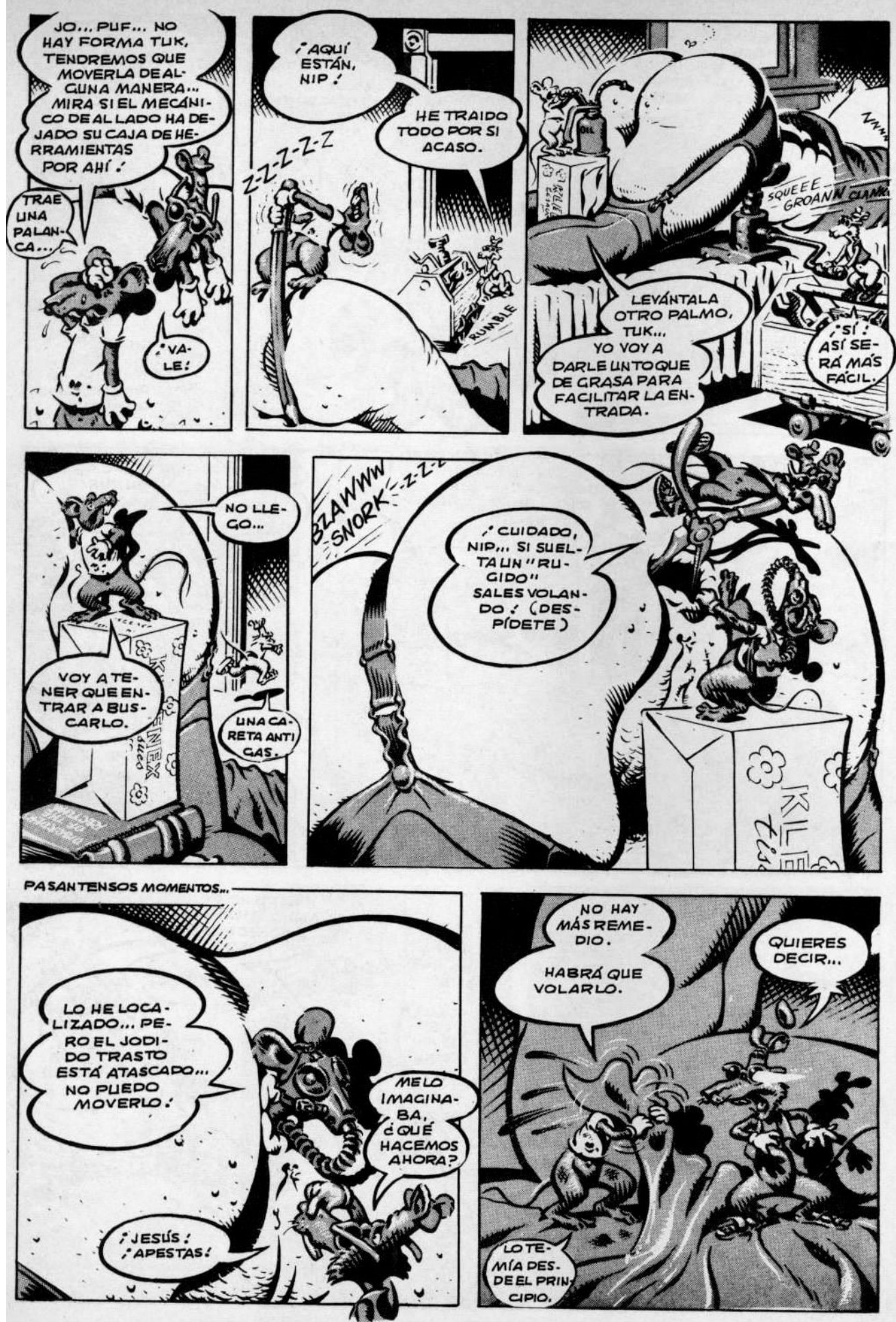

De volta à segurança do covil, surge a grande questão: como se drogar com aquilo? Depois de uma série de tentativas infelizes com os métodos tradicionais, o rato esquentado da dupla resolve tentar uma última forma. Encurvado, as nádegas para o alto e com o desproporcional supositório devidamente 


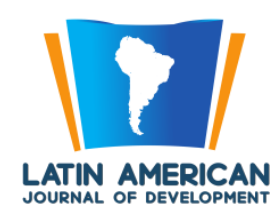

posicionado na altura do ânus, Nip espera que Tuk, com uma marretada certeira, o leve ao deleite ou à morte (FIG. 4).

É fácil entender por que podemos chamar Pasadas anales de narrativa "suja". Os elementos materiais "baixos", como vimos, figuram desde a abertura (ou antes, se considerarmos o título da história) e constituem inclusive o centro de ação dos protagonistas. A história começa parodiando Tom \& Jerry, no fulminante prelúdio em que vemos o crânio do gato esfacelado, o ânus e escroto expostos. Em seguida, acompanhamos a aventura da dupla de ratos (eles próprios criaturas repulsivas) ávidos por drogas, em um ecossistema em grande parcela figurado por seres do "subsolo": drogados e bêbados em um prédio suburbano decadente, abundante em sujeira. E quase no fim atingimos o absurdo escatológico na sequência em que um dos heróis alarga o ânus hemorroidal da mulher com um alicate, para o outro, devidamente equipado, adentrar as profundezas repugnantes e retirar o tão desejado supositório.

FIG. 4 - Passadas Anales, Rand Holmes. Nip chega ao extremo para finalmente conseguir se drogar. Fonte: El Víbora ${ }^{\circ}$ 13-14 (1980).

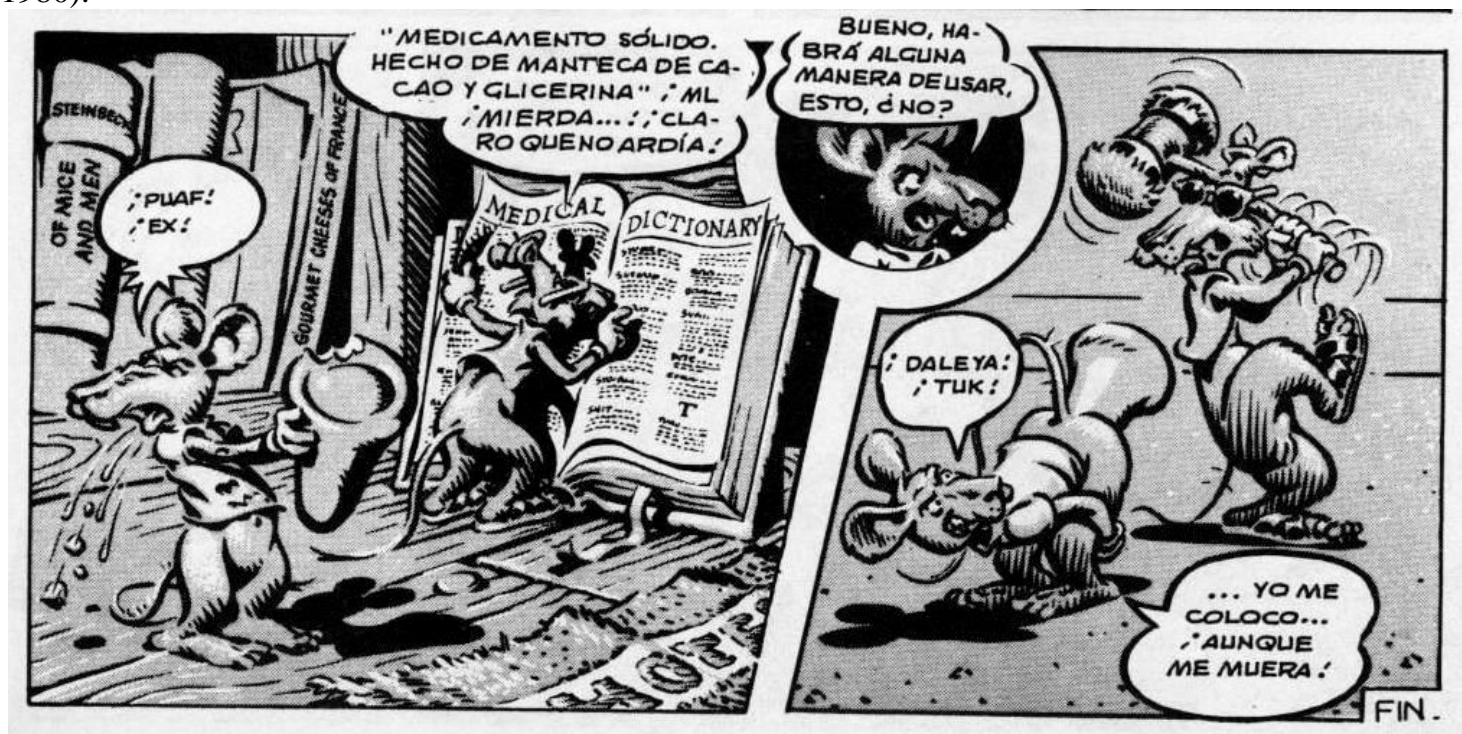

O conto de Holmes tem potencial para figurar entre as mais hilariantes e escatológicas histórias em quadrinhos sobre drogados. Está à altura dos melhores momentos de séries tão famosas como Freak Brothers, de Shelton, ou das loucuras de Emo, Cuco, Niñato e Morgan, os viciados de Gallardo e Mediavilla que também chegam ao ridículo em busca de suas estimadas substâncias. Holmes, com fino senso de humor, já muito conhecido em Herald Hedd e outros trabalhos, recheia a trama com sequências cômicas que poderiam levar às risadas até os mais insensíveis ao humor. No entanto, vale lembrar, sua engenhosidade não é vista apenas no conjunto surpreendente de componentes "sujos" 
habilmente retratados ou nas sensíveis elaborações humorísticas. Ele demonstra absoluto domínio da linguagem dos quadrinhos em seus recursos e procedimentos narrativos.

Holmes, visando a surpresa cômica através da exposição de elementos "baixos" hipertróficos, reserva, em sua estratégia narrativa, as sequências mais grotescas e repulsivas para as últimas páginas. Nelas, acompanhamos todo o esforço dos heróis em torno do invólucro com ópio, indo do ápice coprológico na surpreendente cena em que o rato adentra o ânus escancarado da mulher até a instalação e explosão da bomba.

Percebe-se claramente os artifícios de ocultação e exposição de que se vale Holmes visando reservar o auge da sujeira para as páginas finais da trama. O ânus da mulher, por exemplo, poderia ser mostrado com detalhes já na cena em que ela surge no quarto e faz uso do supositório, mas nesse momento o foco paira sobre a expressão dos ratos observando o jocoso acontecimento, em vez de mostrá-lo propriamente. Ele inclusive usa inteligentemente as viradas de páginas no controle dos componentes "baixos". A virada da quinta para a sexta página traz à tona uma dose cavalar de escatologia. Os elementos que visam o riso do leitor com essa profusão escatológica estão todos lá, estrategicamente planejados.

A engenhosidade narrativa dos principais quadrinistas underground é certamente um aspecto que contribuiu de maneira determinante para o reconhecimento de seus trabalhos. Neste ponto, acreditamos que nosso segundo exemplo cumpra bem a função de ilustrar algo do potencial criativo que é considerado uma das virtudes desses autores. Trata-se do microconto de uma página de Clay Wilson, sem título, publicado em 1968 na icônica revista Zap Comix, nº 3. Nele, Wilson nos apresenta um ousado conteúdo obsceno por meio de uma montagem nada convencional e uma forma bastante original de representação do tempo nos quadrinhos.

O mote de sua trama, muito simples, mas inegavelmente transgressor naqueles anos, se centra numa mulher libidinosa que, caminhando ao lado de seu frígido parceiro, fica excitada ao se deparar com a ejaculação, em proporções homéricas, de um monstro gigantesco (criatura diabólica, de cara simpática, vestindo calça de bolinhas e botas estilizadas) com falo colossal que ali se masturbava (FIG. $5)$. 


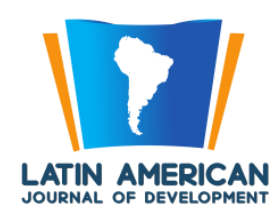

FIG. 5 - Sem título, Clay Wilson. Fonte: Zap Comix (2005).
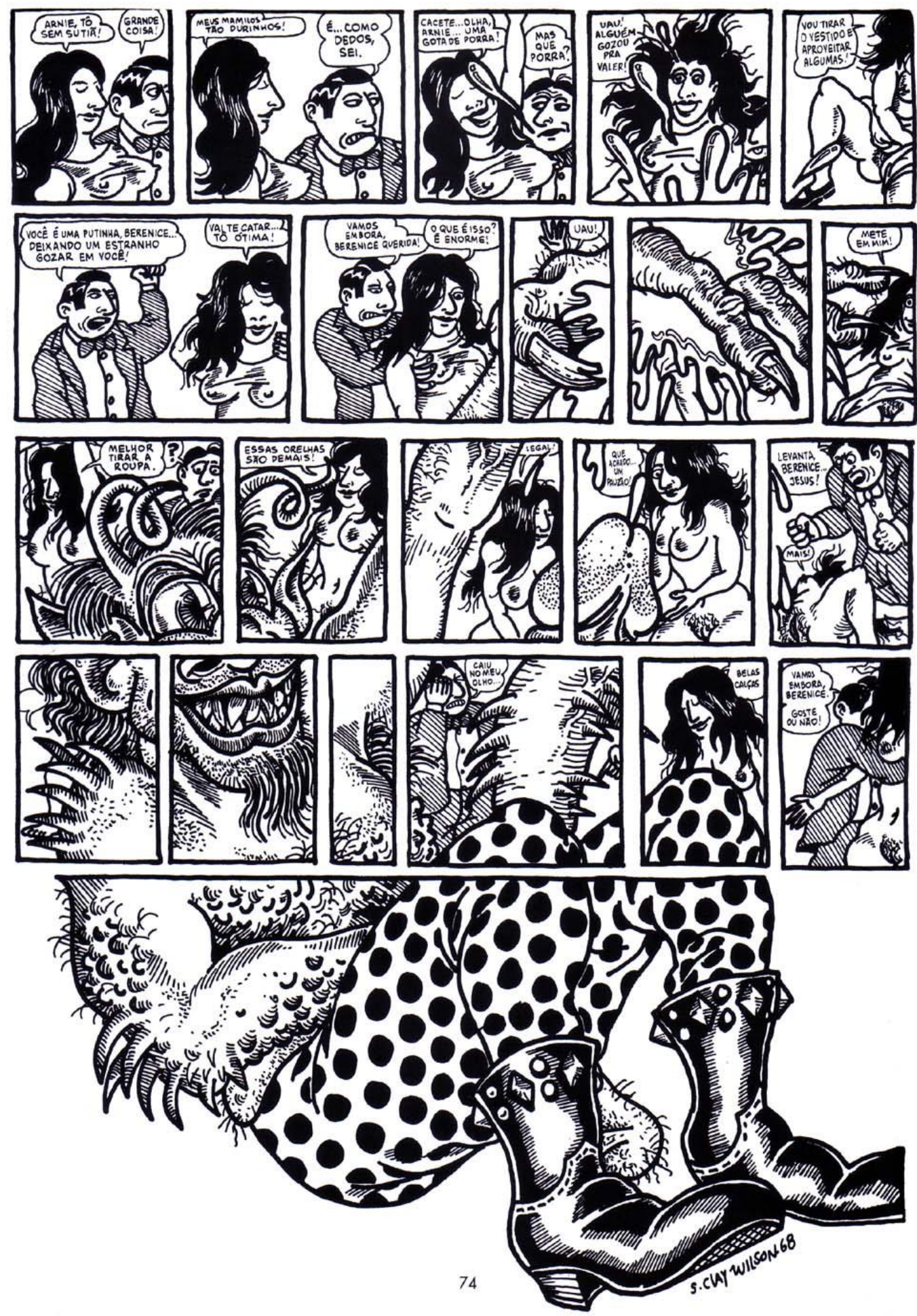

Façamos agora uma decomposição da narrativa para fins analíticos. Observem que há dois planos interpenetrados: um fixo, no qual está a alegre e peculiar criatura de falo e escroto gigantescos ejaculando; e outro seriado, com 21 quadros (dispostos sequencialmente como tradicionalmente ocorre nas histórias em quadrinhos), que apresenta a mulher, o marido e, a cada quadro, uma parte específica 
do plano do diabo sorridente. Os 21 quadros têm significado tanto na relação causal, em que um deságua no outro, criando a sequência (eis a expressão do tempo), quanto em relação, cada um de forma independente (mais ou menos fragmentária ${ }^{9}$ ), com o plano fixo do diabo sorridente (inclusive com as partes vazias).

Só existe inércia no plano do monstro, afinal, ele não se move (é o que acontece igualmente se observarmos cada quadro independentemente, encerrado em si mesmo, no plano dos 21 quadros). $\mathrm{O}$ tempo, o movimento ou, logo, a própria ideia de narrativa passam a existir apenas quando os quadros são entendidos numa associação sequencial, numa sucessão, na relação de causa e efeito que lhes confere um sentido (eis a linha temporal). O plano estático da criatura está sempre no presente, pois ele nunca passa, e está, ao mesmo tempo, em presentes diferentes do tempo no plano fragmentado dos quadros (cada quadro configura, ele próprio, um instante no presente, podendo ser, do mesmo modo, futuro ou passado se relacionado cronologicamente a um quadro anterior ou posterior). Os planos estão interpenetrados e, ainda que haja alguma independência do plano fixo, não há como separá-los sem prejuízo de tão surpreendente composição. Enquanto o monstro permanece o mesmo (embora múltiplo) do começo ao fim, a mulher e o marido se modificam (temporal e espacialmente) somando experiências a cada novo quadro, à medida que vão se relacionando entre eles e com cada parte da criatura engraçada de falo exagerado. A montagem transgressora de Wilson chega a ser perturbadora quando tentamos entendê-la. É paradoxal. Nela, a inércia e a passagem coexistem harmoniosamente, saltando aos nossos olhos.

Clay Wilson chega a falar, com sua erudição característica, em entrevista à revista Heavy Metal (1983, p. 44), sobre a predileção pelo universo material das zonas inferiores:

[...] Em certo sentido é como se eu estivesse predicando... descrevendo o inferno ou algo do tipo. Todos os demais estão descrevendo o céu, assim, creio que vale a pena que siga adiante e descreva o inferno. Entre outras coisas, desenhá-lo resulta mais divertido; a coisa dos anjos e dos demônios. Os Dez Mandamentos dizem: não façam isto, não façam aquilo. De modo que o que faço é desenhar os anjos cercados pela tentação dizendo "não façam tal coisa". Eles não sucumbem, enquanto que os demônios, é claro, tomam parte nas atividades. Vejo meus desenhos majoritariamente como a descrição do inferno com certo grado de cinismo. As fontes remontam a Grünewald, Bruegel, Bosh e artistas do gênero.

Até onde alcança minha memória lembro que sempre quis ser artista. Os quadrinhos eram outra coisa. Não havia uma grande distinção a respeito. Outros sim a faziam. Quando frequentava a universidade de Nebraska, me meti em uma contenda, porque naqueles anos o gênero era o expressionismo abstrato, Kline, Pollock, etc. Ilustrador era o pior insulto que podiam lançarlhe. Meu Deus! Meus desenhos foram condenados porque eram figurativos. Não é um artista, é um ilustrador, porque está aí desenhando desenhos. Ou simplesmente a ideia do texto, dos quadros com as palavras. Era comum classificarem as coisas como quadrinhos quando se deparavam com imagens de personagens falando uns com os outros em vez de chamá-los simplesmente de arte. A história dos quadrinhos, a complicada história de seus diversos estilos, é tão rica como a da maioria dos movimentos artísticos da história (WILSON, 1983, p. 44).

\footnotetext{
${ }^{9}$ No terceiro quadro a mulher vê apenas uma gota de esperma; no sétimo ela já tem uma visão mais ampla do monstro, vendo além das limitações do requadro.
} 
Wilson fala sobre si, sobre sua própria experiência com a narrativa desenhada, mas seu discurso nos apresenta algo que distinguia os quadrinistas underground. Eram inegavelmente legítimos emissários do submundo: primeiro porque preferem falar das esferas materiais inferiores da existência (em vários sentidos), sem restrições, mas também porque a própria linguagem (a história em quadrinhos) que usam para dar sentido ao mundo "inferior" é baixa (subcultural, entretenimento de massa, "figurativa", etc.).

A narrativa desenhada, embora não tão distante do coroamento que estava prestes a acontecer, ainda ocupava um lugar de inferioridade no campo cultural nos anos de 1960, principalmente nos meios intelectuais mais elevados. Mas são nesse período que novas perspectivas críticas surgem como contraponto às representações dominantes, estabelecendo progressivamente um novo estatuto para a narrativa desenhada, que vai colocar definitivamente em questão a ideia de que não passava de um subgênero infantil e didático.

Para Bill Griffth, quadrinista norte-americano reconhecido por seu trabalho na revista Arcade, The Comics Revue ${ }^{10}$ e colaborador em uma infinidade de títulos underground ou alternativos, a narrativa gráfica que precedeu o underground não tinha conseguido, por uma série de razões, atingir o nível de maturidade que a colocasse no mesmo nível de outras formas de arte como a literatura ou seu primo próximo, o cinema. Se por um lado era exagerado o estigma de material exclusivamente infantil, seria exagero igual equiparar os quadrinhos a linguagens artísticas que estavam em nível superior em termos teóricos e práticos (Sherman, 1984, p. 818). Griffth defende que é com o underground que os quadrinhos se tornam arte:

[...] reconheço a maestria dos criadores da [editora] E.C., assim como de outros inovadores ou de desenhistas espontâneos dos anos quarenta e cinquenta.

O que realmente é importante reconhecer é que os comics, até então, seguiam sendo uma arte que não havia evoluído, apesar das proezas técnicas e a execução precisa. Se encontravam reprimidos pelos tempos, restringidos, atados pela lei, pelas realidades econômicas e a reação do público. Por outro lado, os comix "underground" deram enormes passos para alcançar a luz do dia como arte evoluída, juntando elementos e ideias diversas.

Reconheço que há pontos fracos e que vez por outra houve movimentos em falso, porém, em sua melhor faceta são reveladores, catárticos, belos ${ }^{11}$. Induzem a pensar, ao conhecimento; têm uma gama quase ilimitada de temas e significados. Te pegam desprevenido. Há momentos de genuína iluminação entre os melhores deles. (Sherman, 1984, p. 818).

\footnotetext{
${ }^{10}$ Publicação lançada em 1975, editada por Spiegelman e Griffin, que contava com a participação de figurões do underground como Robert Crumb, Clay Wilson, Gilbert Shelton, entre outros.

${ }^{11}$ A ideia de beleza da qual fala Griffth, como podemos deduzir, tem um sentido distinto das noções tradicionais de beleza, para as quais esses quadrinhos seriam normalmente "feios" e "desprezíveis".
} 
Chega a ser curioso o fato de que o definitivo reconhecimento cultural dos quadrinhos tenha acontecido ao mesmo tempo em que seus conteúdos passam a investir mais do que nunca em excrescências e obscenidades. Mas, como demonstramos, a qualidade desses quadrinhos nunca esteve limitada à originalidade dos conteúdos então mobilizados. Estava também na forma como as histórias eram narradas, na forma como a linguagem era experimentalmente e criativamente utilizada. Assim, sensíveis às possibilidades significativas dessa linguagem e abertos à experimentação, os melhores escritores underground se mostraram capazes de desenvolver novas formas de fazer história em quadrinhos e, consequentemente, abriram novos caminhos para o gênero.

\section{CONSIDERAÇÕES FINAIS}

Os quadrinhos underground foram verdadeiras máquinas de gerar polêmicas desde os seus primeiros passos. A liberdade de que dispunham seus escritores os permitiu atingir domínios da narrativa gráfica até então pouco desbravados. Domínios que muitas vezes eram indigestos para a maioria das pessoas. Até por isso enfrentaram a oposição daqueles que os viam como destinados a corromper os jovens da época. Eram tidos como verdadeiras ervas daninhas.

Foi com base nesse tipo de ideia que em 1969 a revista Zap Comix se tornou alvo de processos e foi considerada legalmente obscena pelas autoridades estadunidenses - a primeira história em quadrinhos a alcançar tal status. E isso acontece justamente quando a publicação atinge, em seu quarto número, o ápice da exploração de temas "sujos" (mérito sobretudo de Robert Crumb por sua famosa história Joe Blow, em que aborda com seu cinismo usual temas como a pedofilia e incesto). Logistas e distribuidores chegaram a ser presos nos Estados Unidos por simplesmente ter a edição em seus estoques. Mas talvez o momento mais representativo do que significavam aqueles quadrinhos para o senso comum está na declaração do juiz Joel Tyler, de Nova Iorque, que julgou o caso da Zap Comix $n^{o}$ 4: "Essa publicação é feia, barata e degradante" (Estren, 2012, p. 232). E considerou que uma pessoa normal poderia ter sua moral "irreparavelmente corrompida" se lesse aquele material. Rogério de Campos, editor da edição brasileira da Zap Comix, lembra que a declaração do juiz Tyler levou algumas pessoas a se perguntarem se a moral do próprio juiz não "teria se corrompido irreparavelmente depois do contato íntimo com a revista que ele fora obrigado a ler em razão do julgamento" (Campos, 2005, p. 29).

Ainda que fossem concebidos para um público adulto, os conteúdos mobilizados naqueles quadrinhos não podiam ser tolerados pela moral comum - passavam dos limites, como vimos na declaração do juiz. Mas as polêmicas podem ter também contribuído na popularização do underground, que se internacionalizou e não parou de angariar adeptos na década seguinte ao seu surgimento. $\mathrm{O}$ fato é que, se uma parcela expressiva da sociedade não aceitava os quadrinhos sujos, eles tinham também 
o seu público cativo, que no início contribuiu para a formação de uma espécie de nicho, e não muito depois, somados a uma legião de novos leitores, possibilitou a consolidação comercial do comix.

Olhando por alto, talvez o que mais salte aos olhos seja realmente a obsessão pelo universo material baixo, a sujeira em excesso, tudo o que significava tabu. Todavia, como observamos, a narrativa gráfica underground não pode ser definida levando-se em consideração apenas conteúdos desencarnados de suas formas - a perspectiva nesse caso se tornaria muito parcial e consequentemente incompleta. $\mathrm{O}$ aspecto formal é indispensável para entendermos como o processo de amadurecimento da narrativa gráfica passa também pela engenhosidade estética e narrativa dos grandes autores da linha suja. Os quadrinhos amadureceram e seu reconhecimento como forma legítima de arte e importante meio de expressão cultural não podia mais ser adiado. É a partir dali que uma crítica especializada emerge e passa a se dedicar a pensar nos pormenores essa história há muito desprezada.

Os comix estadunidenses abriram tantas veredas que seria preciso um novo artigo para tratar exclusivamente do assunto. Para se ter uma ideia, até um gênero tão importante quanto a autobiografia em quadrinhos, fundamental para o desenvolvimento da novela gráfica contemporânea, como pontuou Santiago García (2012, p. 174), nasce no seio do underground. As palavras de Bill Griffith, citadas anteriormente, sobre uma revolução promovida pelos comix, parecem fazer total sentido se considerarmos tudo o que foi possível a partir deles. A narrativa desenhada underground não vencia somente as limitações do Comics Code e da infantilização, transgredia também as limitações de gêneros tradicionais e de imposições comerciais de toda ordem. Um movimento que muitas vezes é lembrado mais pelo seu gosto pela sujeira, que é sem dúvida um de seus traços principais, do que por outros aspectos igualmente fundamentais para contextualizá-lo devidamente na história dos quadrinhos. 


\section{REFERÊNCIAS BIBLIOGRÁFICAS \\ REFERENCIAS BIBLIOGRAFICAS}

BAKHTIN, Mikhail. Cultura Popular na Idade Média e no Renascimento - O Contexto de François Rabelais. São Paulo: Hucitec, 1987.

CAMPOS, Rogério de. Alter America, alter heros. In: Zap Comix. São Paulo: Conrad, 2005.

CRUMB, Robert; WILSON, Clay et al. Zap Comix. São Paulo: Conrad, 2005.

DOPICO, Pablo. Esputos de papel - La historieta underground española. In: Arbor - Ciencia, pensamento e cultura. Madri: Consejo Superior de Investigaciones Científicas, vol. 187, $\mathrm{n}^{\mathrm{o}}$ extra 2, 2011, pp. 169-181.

ESTREN, Mark James. A history of underground comics. California: Ronin Publishing, 2012.

GARCIA, Santiago. A novela gráfica. São Paulo: Martins Fontes, 2012.

HOLMES, Rand. Pasadas anales. In: El Víbora. Barcelona: Ediciones La Cúpula, 1980, nº 13-14.

JONES, Gerard. Homens do amanhã. São Paulo: Conrad, 2006.

SHERMAN, Bill. El "underground" norteamericano. In: COMA, Javier (org.). Historia de los comics. Barcelona: Toutain Editor, 1984, Fascículo 30.

WILSON, Clay. Entrevista para Brad Balfour. In: Heavy Metal. New York: HM Communications, 1983, vol. VI, nº 12 . 